DISTRIBUTION STATEMENT A: Approved for public release; distribution is unlimited.

\title{
Fine-scale Survey of Right and Humpback Whale Prey Abundance and Distribution
}

\author{
Joseph D. Warren \\ School of Marine and Atmospheric Sciences \\ Stony Brook University \\ 239 Montauk Hwy \\ Southampton, NY 11968 \\ phone: (631) 632-5045 fax: (631)632-5070 email: Joe.warren@stonybrook.edu
}

Award Number: N00014-09-1-0484

\section{LONG-TERM GOALS}

The long-term goals of this project are to describe the distribution and abundance of zooplankton prey over small spatial and temporal scales and to use this data to provide information which will be of use to scientists studying whale behavior. We are working closely with scientists studying the behavior and movement of both right and humpback whales and the combination of the two data sets will provide us information into how the behavior of marine mammals is affected by their prey.

\section{OBJECTIVES}

This project will measure the abundance and distribution of the major prey species (zooplankton and nekton) of humpback and right whales as well as the spatial and temporal scales (relevant to foraging and feeding marine mammals) that the prey field varies over. Without this information, behavioral studies of marine mammals and their responses to various stimuli may be limited in their conclusions as food presence and availability is likely an extremely strong factor in determining marine mammal behavior. In order to collect this critical information, we will:

(1) Identify the prey type (e.g. copepod, krill, fish) and numerical abundance of zooplankton and nekton in the vicinity of marine mammals by integrating multiple frequency acoustic survey data with net and video measurements (Foote and Stanton, 2000; Warren et al., 2003). The distribution and numerical density of prey (in both the horizontal and vertical dimensions) relative to predator presence and behavior will be measured. We will measure the variability of the prey field over length and time scales ( $1 \mathrm{~m}$ - 10s km, $10 \mathrm{sec}$ - days) that are important for right and humpback whale feeding behavior and success.

(2) Measure environmental parameters (hydrographic and meteorologic) during these surveys that may be correlated with marine mammal behavior, the presence of prey species, or sub-surface acoustic scattering processes (Warren et al., 2003; Lawson et al., 2004).

(3) Collect visual observations of surfacing marine mammals and their behavior during the survey which can be integrated with the prey field data and observations from other vessels or instrumented tags. 


\section{Report Documentation Page}

Form Approved

OMB No. 0704-0188

Public reporting burden for the collection of information is estimated to average 1 hour per response, including the time for reviewing instructions, searching existing data sources, gathering and maintaining the data needed, and completing and reviewing the collection of information. Send comments regarding this burden estimate or any other aspect of this collection of information,

including suggestions for reducing this burden, to Washington Headquarters Services, Directorate for Information Operations and Reports, 1215 Jefferson Davis Highway, Suite 1204, Arlington

VA 22202-4302. Respondents should be aware that notwithstanding any other provision of law, no person shall be subject to a penalty for failing to comply with a collection of information if it

does not display a currently valid OMB control number.

\begin{tabular}{|c|c|c|}
\hline $\begin{array}{l}\text { 1. REPORT DATE } \\
\mathbf{2 0 1 0}\end{array}$ & 2. REPORT TYPE & $\begin{array}{l}\text { 3. DATES COVERED } \\
\mathbf{0 0 - 0 0 - 2 0 1 0} \text { to 00-00-2010 }\end{array}$ \\
\hline \multirow{3}{*}{\multicolumn{2}{|c|}{$\begin{array}{l}\text { Fine-scale Survey of Right and Humpback Whale Prey Abundance and } \\
\text { Distribution }\end{array}$}} & 5a. CONTRACT NUMBER \\
\hline & & 5b. GRANT NUMBER \\
\hline & & 5c. PROGRAM ELEMENT NUMBER \\
\hline \multirow{3}{*}{\multicolumn{2}{|c|}{ 6. AUTHOR(S) }} & 5d. PROJECT NUMBER \\
\hline & & 5e. TASK NUMBER \\
\hline & & 5f. WORK UNIT NUMBER \\
\hline \multicolumn{2}{|c|}{$\begin{array}{l}\text { 7. PERFORMING ORGANIZATION NAME(S) AND ADDRESS(ES) } \\
\text { Stony Brook University,School of Marine and Atmospheric Sciences, } 239 \\
\text { Montauk Hwy,Southampton,NY,11968 }\end{array}$} & $\begin{array}{l}\text { 8. PERFORMING ORGANIZATION } \\
\text { REPORT NUMBER }\end{array}$ \\
\hline \multirow{2}{*}{\multicolumn{2}{|c|}{ 9. SPONSORING/MONITORING AGENCY NAME(S) AND ADDRESS(ES) }} & 10. SPONSOR/MONITOR'S ACRONYM(S) \\
\hline & & $\begin{array}{l}\text { 11. SPONSOR/MONITOR'S REPORT } \\
\text { NUMBER(S) }\end{array}$ \\
\hline
\end{tabular}

12. DISTRIBUTION/AVAILABILITY STATEMENT

Approved for public release; distribution unlimited

13. SUPPLEMENTARY NOTES

14. ABSTRACT

15. SUBJECT TERMS

16. SECURITY CLASSIFICATION OF:

\begin{tabular}{c|c|c}
$\begin{array}{c}\text { a. REPORT } \\
\text { unclassified }\end{array}$ & $\begin{array}{c}\text { b. ABSTRACT } \\
\text { unclassified }\end{array}$ & $\begin{array}{c}\text { c. THIS PAGE } \\
\text { unclassified }\end{array}$
\end{tabular}

17. LIMITATION OF ABSTRACT

Same as

Report (SAR)
18. NUMBER 19a. NAME OF

OF PAGES RESPONSIBLE PERSON

9 


\section{APPROACH}

\section{Acoustic Surveys}

Acoustic backscatter data is collected continuously from a research vessel in the same area as that of the tagging operations. Multiple frequency acoustic data are used to discriminate between different types of scatterers in the water column with the primary distinction being between zooplankton (copepods or krill in this area) and nekton (small fish such as sand lance). The general approach is to conduct a regular grid-like survey while our collaborators are attempting to tag a whale. Once a whale is tagged, then the vessel will follow the whale (as best as possible) so that we can describe the prey field that the tagged animal is experiencing.

\section{Net Tow Sampling}

At regular intervals during the survey operations, we conduct vertical net tows to identify the species of interest that occur in the water column as well as to provide information necessary to convert the acoustic data into estimates of biomass density $\left(\mathrm{mg} / \mathrm{m}^{3}\right)$ or numerical abundance $\left(\# / \mathrm{m}^{3}\right)$. At each station, a vertical net tow to a depth of $5 \mathrm{~m}$ is conducted and when time permits we also conduct a net tow of the shallower of the full water column or $20 \mathrm{~m}$ depth. These two types of sampling allow us to determine if there are differences within the water column in either the type or abundance of zooplankton present. Additional measurements include the use of a video camera system to collect in situ information about animal identification and orientation in the water column.

\section{Hydrography}

At the net tow sampling stations, hydrographic data are collected with a SeaBird 19+ CTD. This sensor provides information on temperature, salinity, density, dissolved oxygen, and fluorescence at a vertical resolution of 10s of $\mathrm{cm}$ for the water column. These data are particularly useful in determining if there are physical or biological factors that may affect the distribution and abundance of zooplankton prey in the water column.

\section{Surface Observations}

During transit, survey, and station; surface observers record the presence, distance and bearing (estimated), abundance, species, and behavior (when possible) of any marine mammals near the vessel. These data are collected to supplement the observations made by our collaborators and will provide us with a larger data set of predator observations to relate to our prey information. In addition, the observers record basic weather and sea state information.

\section{WORK COMPLETED}

We completed our final field season during spring 2010 with the research vessel and field team based out of Provincetown, MA for a three week period from March $25^{\text {th }}$ to April $17^{\text {th }}$. Weather precluded field operations roughly $50 \%$ of the study period. Both the zooplankton (Warren-led) and D-Tag (Parks-led) field teams were based from the RV Stellwagen with the D-Tag operations occurring from an inflatable vessel deployed from the RV Stellwagen. Vessel location and meteorological data were collected whenever the vessel was underway or on station. Acoustic backscatter data were collected from a towfish (equipped with 38, 120, 200, and $710 \mathrm{kHz}$ scientific echosounders and a $600 \mathrm{kHz}$ Acoustic Doppler Current Profiler) deployed from the starboard side of the RV Stellwagen (Figure 1). Two modes of survey were used: standard straightline transects or animal-specific surveys around 'DTAG'ed baleen whales. In addition to the acoustic transect data, we completed 15 CTD stations, 54 zooplankton net tow stations, 12 video plankton recorder stations, several water sample collections for 
bulk chlorophyll analysis, and several hundred surface observations of marine mammal predators (primarily humpback and right whales). The majority of survey operations occurred during the day, although we did conduct one overnight study.
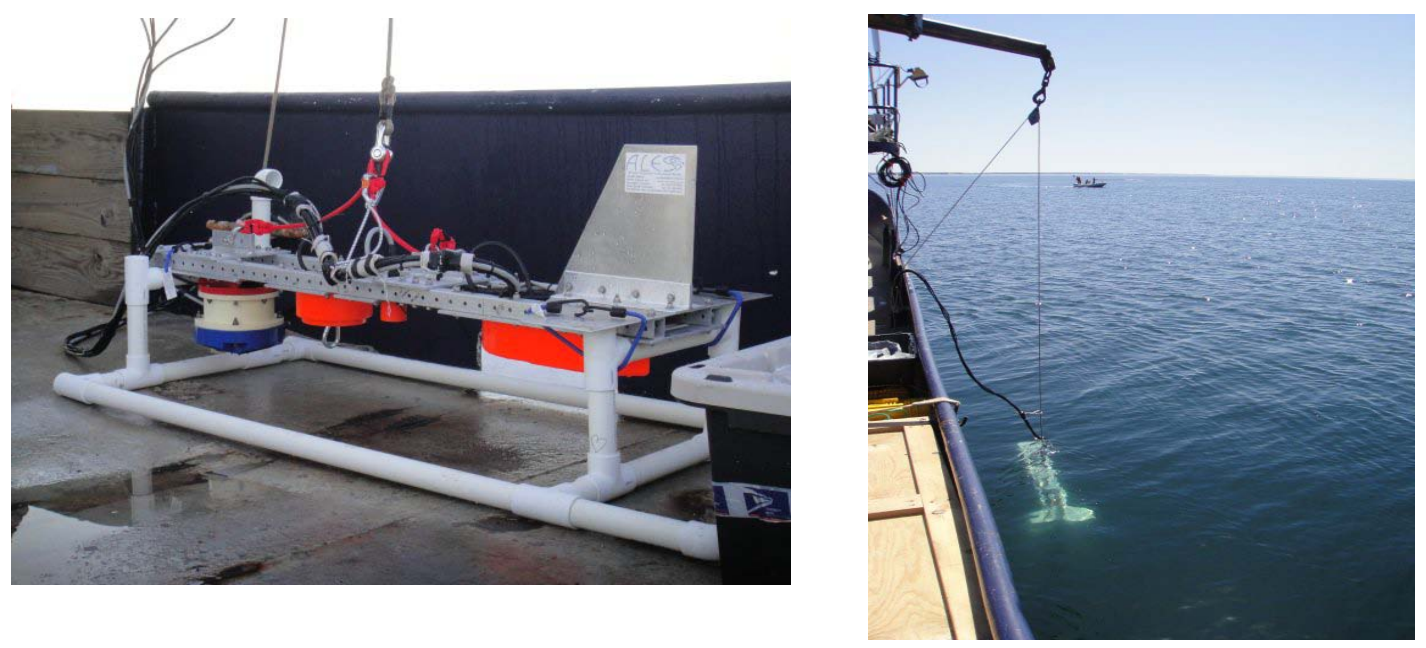

Figure 1. A towfish (left) equipped with (from left to right) a $600 \mathrm{kHz} A D C P, 120 \mathrm{kHz}$ split-beam transducer, $710 \mathrm{kHz}$ single-beam transducer, and 38/200 kHz single-beam transducers. The towfish deployed from the RV Stellwagen (right) with the D-Tag vessel searching for whales.

\section{RESULTS}

Analysis of our data sets is ongoing, however our preliminary results indicate:

* Net and video data indicate that near foraging right whales, small copepods were the dominant zooplankton and were concentrated in the upper 5 meters of the water column. Video data indicate that near foraging humpback and fin whales, herring and sand lance were the dominant acoustic scatterer and were found at various depths.

Preliminary analysis of our net tow samples suggest that copepods were the primary zooplankton in the water column in Cape Cod Bay although the biomass varied spatially both horizontally and vertically. Currently we are identifying and counting the samples collected during the 2010 field season. Preliminary data indicate that typical numerical densities were between 500 and 2500 individuals per cubic meter. Differences were observed both spatially (over large and small horizontal distances and vertically) and temporally. In general, samples from Cape Cod Bay were primarily small (0.5 to $3 \mathrm{~mm}$ ) Calanus finmarchicus or juvenile copepods (species unknown). At most zooplankton stations, multiple tows were conducted (Figure 2): a $1 \mathrm{~m}$ very shallow (VS) tow, a $5 \mathrm{~m}$ shallow (S) tow, and a 20 $\mathrm{m}$ deep (D) tow. In general, numerical densities of copepods were similar between the shallow and deep tows suggesting that most copepods were found in the upper $5 \mathrm{~m}$ of the water column. Our sampling was conducted with a $0.5 \mathrm{~m}$ diameter ring net with a 150 micron mesh in order to collect small crustacean zooplankton therefore nekton will not be captured by it. During the 2010 field season, we also deployed additional video samplers. A Video Plankton Recorder (VPR) was used to 
collect vertical profiles of the zooplankton in the water column (Figure 3) while an underwater video camera was deployed to determine the identity of nekton scattering layers that were found.

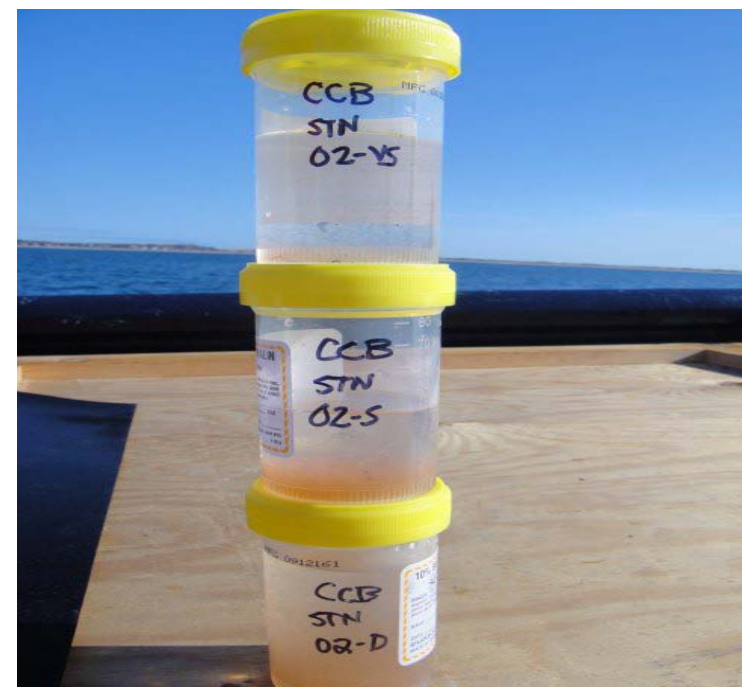

Figure 2. Multiple net tows (VS [0-1m], S[0-5m], D[0-20m]) to different depths at stations showed that near-surface (0 to $5 \mathrm{~m}$ ) waters contained the majority of zooplankton. The zooplankton were primarily small (0.5 to 3mm length) copepods (C. finmarchicus).
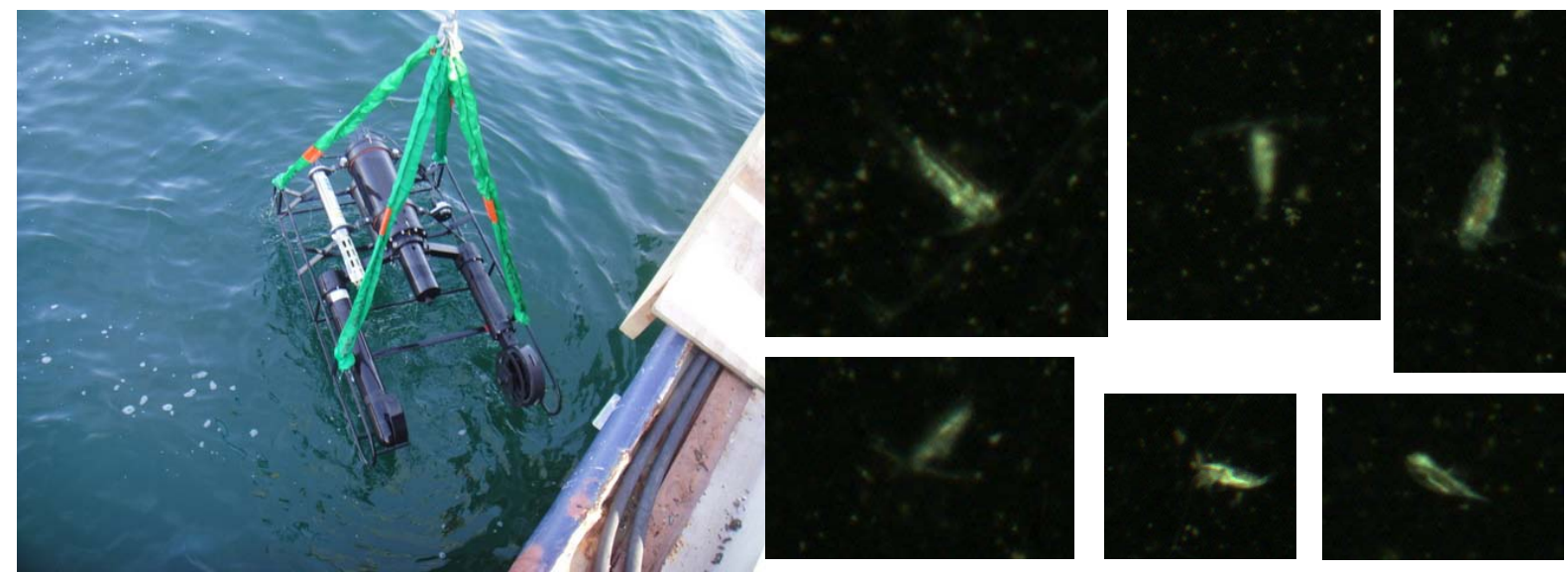

Figure 3. The video plankton recorder (VPR) (left) was deployed to collect data on the vertical distribution of zooplankton in Cape Cod Bay. The instrument produces images of animals (such as the copepods shown here) which are used to calculate numerical density which can be compared to the acoustic and net tow data.

* Acoustic backscatter data show that small scatterers (copeopds) were concentrated near the surface and that their abundance varied over small (10s to 100s of meters) horizontal distances. For this study, animals a few mm in length (such as the copepods found in Cape Cod Bay in the spring) can only be detected acoustically at high frequencies. Both our $600 \mathrm{kHz}$ and $710 \mathrm{kHz}$ acoustic systems showed high levels of scattering in the very near surface waters (Figure 4). It is important to note that other near-surface scattering processes such as bubbles can be strong acoustic scatterers (at all 
frequencies). By comparing the data from our lower frequencies $(38,120$, and $200 \mathrm{kHz})$ and our higher frequencies (600 and $710 \mathrm{kHz}$ ), we are able to determine that zooplankton and not other scattering processes are responsible for the near-surface scattering that was observed. We are in the process of developing an estimate for the Target Strength of the copepods found in these waters so we can convert our acoustic data to estimates of numerical density that can be compared with data from our other instrumentation.

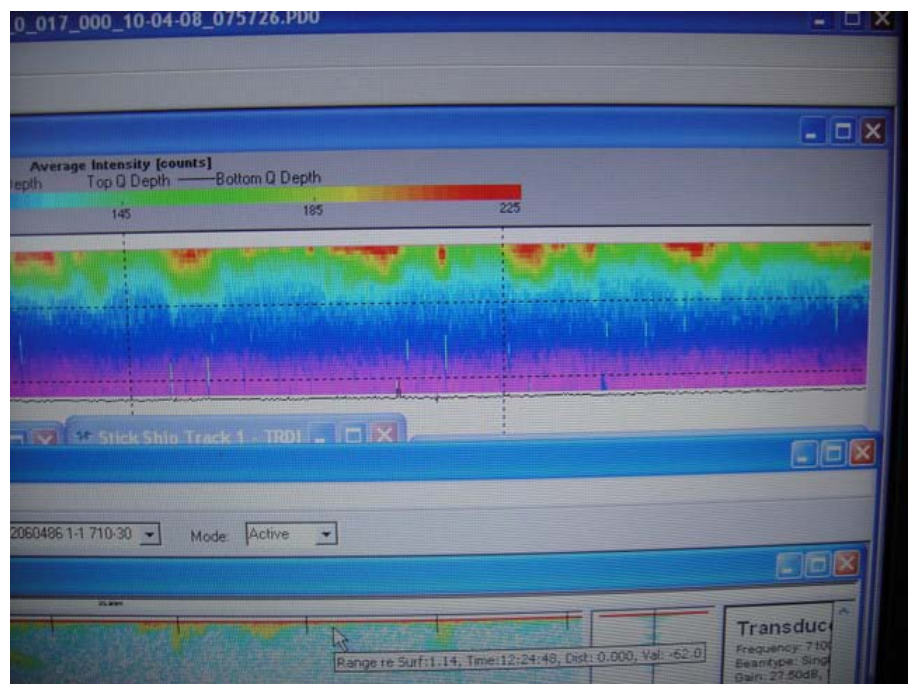

Figure 4. A picture of the echograms from the $600 \mathrm{kHz}$ ADCP (top) and $710 \mathrm{kHz}$ echosounder (bottom). Both show strong scattering patches (which net tows confirmed were copepods) in the upper 1 to $5 \mathrm{~m}$ of the water column which varied over spatial distances of tens of meters. The color scales are different between the two acoustic systems.

\section{* Acoustic data show that in other areas, nekton (herring or sand lance) were the strongest scatterers in the water column.}

Acoustic backscatter data from multiple frequencies can be used to identify and discriminate between different acoustic scatterers. When scatterers are different sizes (copepods, fish), this can be done by examining whether backscatter at lower frequencies is similar (fish) or less than (copepods) than the backscatter at high frequencies. We are attempting to determine whether we can discriminate (acoustically) between the two dominant nekton species (herring, sand lance) that were encountered during this study (Figure 5). Video data were used to identify the scatterers of some patches and we are investigating whether theoretical scattering models can be used to discriminate and identify between these two nekton. 


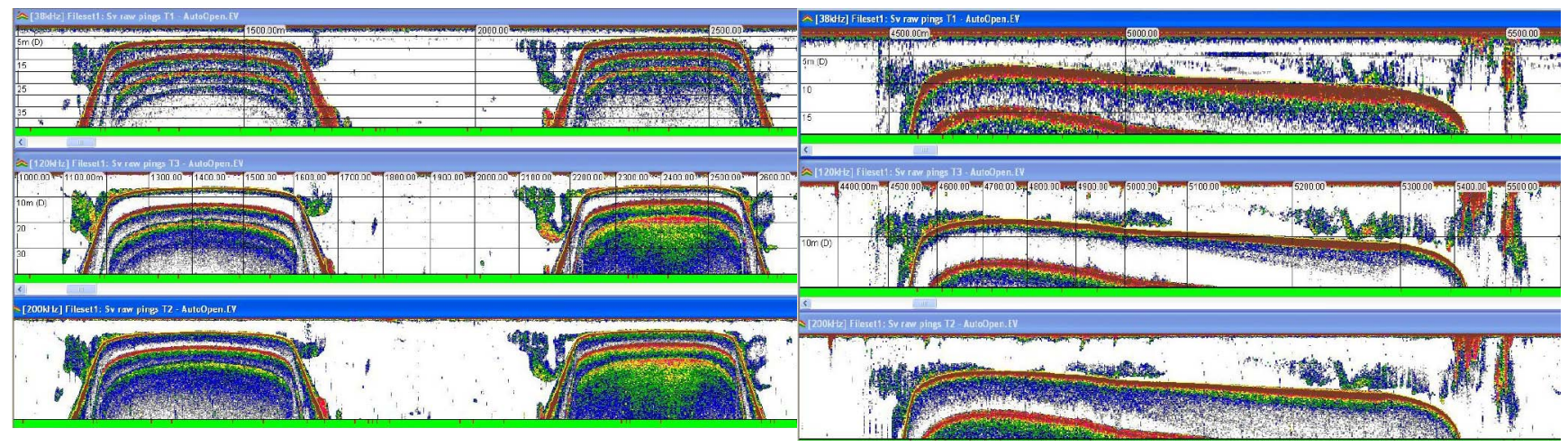

Figure 5. Echograms from the 38 (top), 120 (middle), and 200 (bottom) kHz echosounders show large aggregations of scatterers that were found as the research vessel surveyed the waters near a $D$ TAGed humpback whale. The left panel shows scattering patches ranging from $10 \mathrm{~m}$ to $35 \mathrm{~m}$ in depth, while the right panel shows a close up of patches that were found on and above the bottom (water depth $\sim 10 \mathrm{~m}$ ) as well as near and at the surface. Identification and discrimination between scattering from herring and sand lance is currently being attempted using theoretical scattering models and video and acoustic data collected in this study.

* Location and behavior of right and humpback whales are related to the presence, location, and density of their preferred prey.

By combining acoustic backscatter data from surveys conducted around tagged baleen whales, it was found that the whale's location and behavior were related to the abundance and distribution of their prey. When possible, our instrument was towed near to a tagged animal. If the animal was transiting, we would follow the whale at a distance of about $100 \mathrm{~m}$. If the animal was not moving quickly or moving back and forth, we would move in a large circle with the whale at the center. These data allow us to measure what the preyfield was close to the tagged whale. We wanted to avoid having the presence of our vessel and echosounder affect the behavior of the tagged animal so our data are not colocated (in time or space) to the tagged animal, but are (generally) collected within $150 \mathrm{~m}$ and a minute or two of the whale passing through a particular area. Given the variability in the preyfield that we measured, we can estimate how accurate our estimates of the preyfield are in terms of the difference between the whale and our measurement locations.

Using D-TAG data provided by our collaborator (Susan Parks, Penn State), we can create figures showing the behavior of the whale and an approximation of its preyfield. For right whales, copepods are the prey species and were found in the near surface which is also where the whales spent the majority of their time (Figures 6 and 7). For humpback whales, fish (herring or sand lance) are the preferred prey. The vertical distribution of nekton varied spatially, and the behavior of the humpback whale changed as the prey distribution did (Figure 8). We are currently analyzing these data and attempting to develop metrics that best quantify how these two factors (prey density, predator behavior) are inter-related. It is interesting to note the different behaviors of the two tagged whales are both correlated with the presence of their zooplankton or nekton prey. And that the tagged whale behavior can be very consistent (in the case of the right whale) or vary quite a bit (as in the case of the humpback whale). It should be noted that we are currently analyzing the data from all the tagged whales, but we will still have a fairly small sample size from this study. 


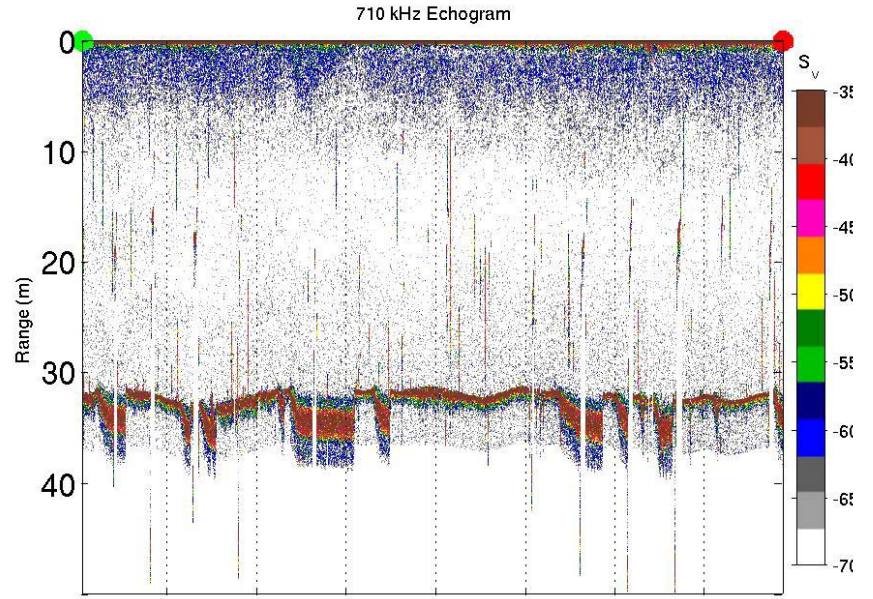

95.4495 .4695 .4895 .595 .5295 .5495 .56

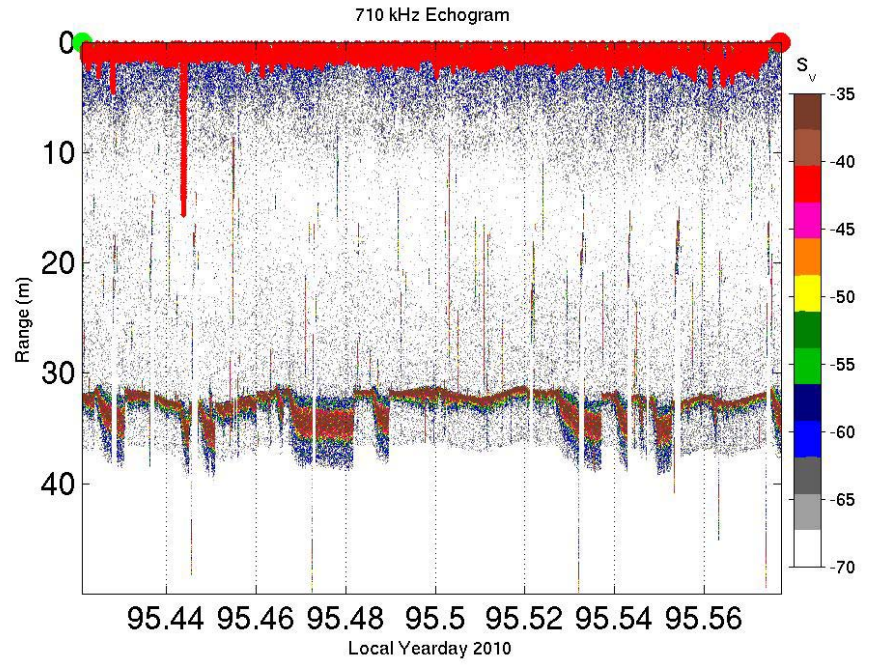

$95.4495 .4695 .48 \underset{\text { Local Yearday } 2010}{90.5295 .5495 .56}$

Figure 6. Echogram from the $710 \mathrm{kHz}$ echosounder (left) which shows that scattering (from copepods) was strongest in the upper 5 meters of the water column. When the vertical position of a tagged right whale is overlaid (red line in the right panel) on the echogram, it is apparent that the animal spent the majority of its time where prey abundance was highest. The echogram represents a roughly 2 hour period and the acoustic and tag data are not georeferenced to one another although the acoustic data were collected within a few hundred meters of the right whale.

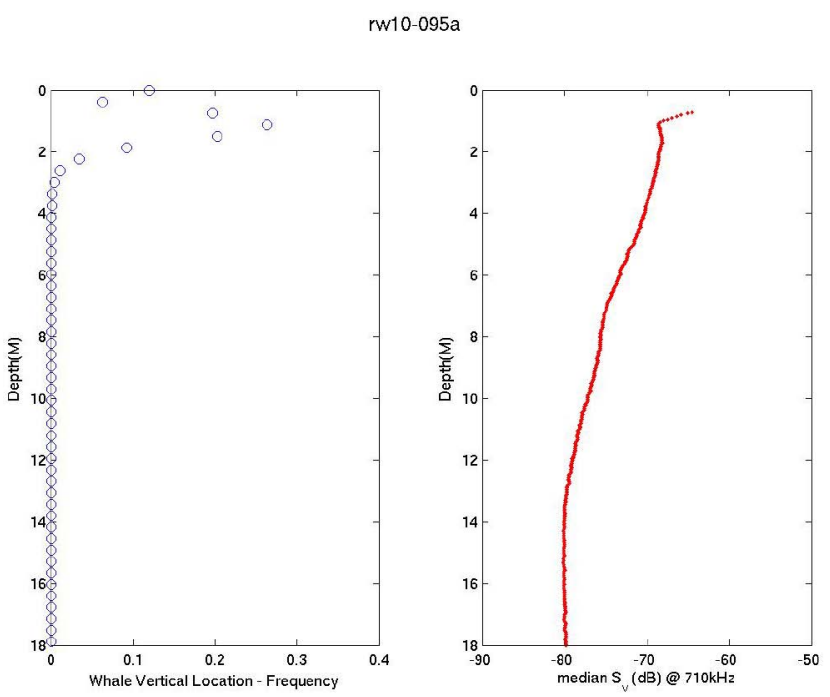

Figure 7. The vertical distribution of the time spent by the right whale vertically in the water column (left) shows strong agreement with the median acoustic backscatter profile collected from the 710 $\mathrm{kHz}$ echosounder. Data in this figure is from the same time period as in Figure 6, although only the upper $18 \mathrm{~m}$ (the deepest depth the whale was at) are shown. 

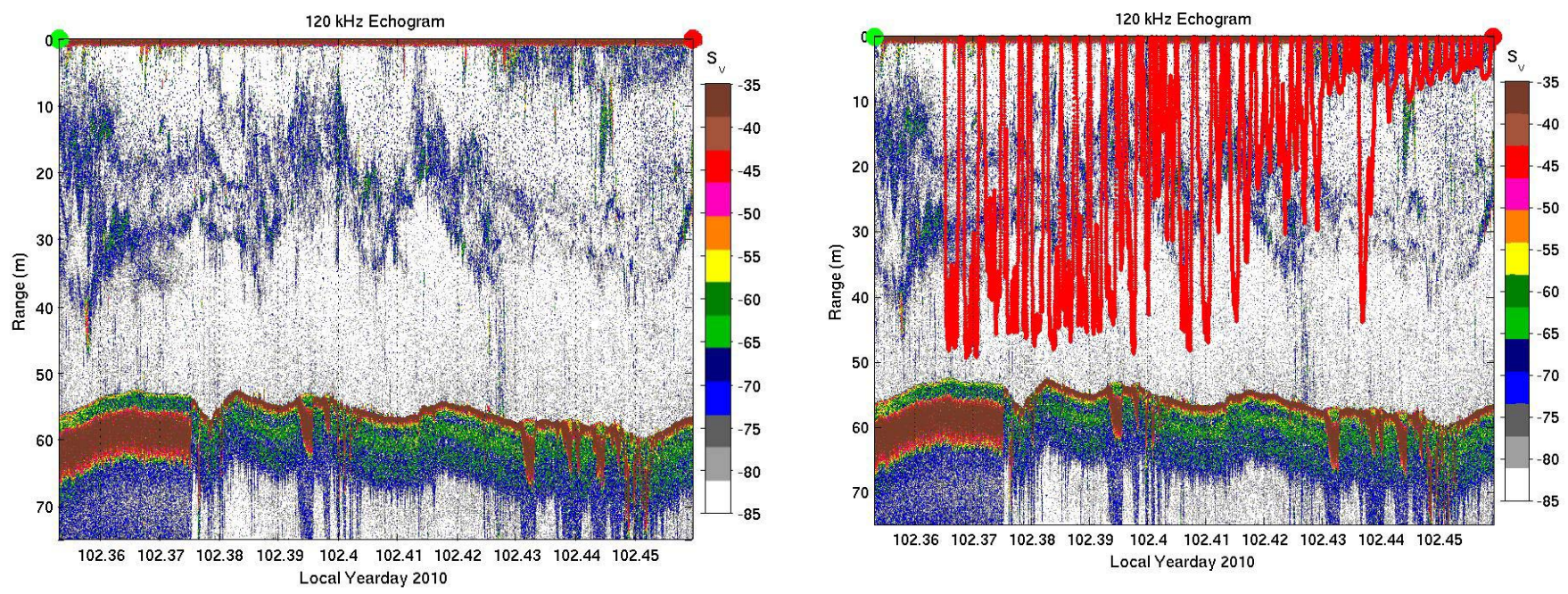

Figure 8. Echogram from the $120 \mathrm{kHz}$ echosounder (left) which shows the distribution of acoustic backscatter (from nekton) varied vertically and horizontally in the water column. When the vertical position of a tagged humpback whale is overlaid (red line in the right panel) on the echogram, it is apparent that the animal dove to depths and (presumably) foraged where prey abundance was highest. As the vertical distribution of prey changed over the study period, the whale's behavior changed as well with shallower dives as the scatterers were concentrated nearer to the surface. The echogram represents a roughly 2 hour period and the acoustic and tag data are not georeferenced to one another although the acoustic data were collected within a few hundred meters of the humpback whale.

\section{IMPACT/APPLICATIONS}

The data collected in this project will form the basis for understanding the prey environment that right and humpback whales encounter in these regions. In order to assess marine mammal behavior, an understanding of the distribution and abundance of their prey will be critical to understand their feeding behavior. We are attempting to describe the spatial (both horizontal and vertical) and temporal patterns that occur in the prey (zooplankton and small nekton) for these two species in conjunction with scientists measuring the movement and behavior of these animals. If we can determine that there are patterns that exist in the whale's preyfield and that the behavior of the whales is correlated with these patterns then that information will be useful for a variety of purposes including a better understanding of the foraging ecology of right and humpback whales and the processes that affect their behavior and movements which can assist conservation efforts and the mitigation of anthropogenic impacts on these animals.

\section{RELATED PROJECTS}

This project works closely with the Parks/Wiley project "Fine-scale Focal Dtag Behavioral Study of Diel Trends in Activity Budgets and Sound Production of Endangered Baleen Whales in the Gulf of Maine” to coordinate field activities and logistics, sampling plans, and data analysis. The 2009 and 2010 field seasons were a success in terms of coordination of the sampling for this and the Parks/Wiley project in that concurrent data were collected on the zooplankton populations and their marine mammal predators. We anticipate several joint-authored publications to result from this project and 
have begun to outline and write several of these. In addition, we coordinated our sampling with that done by the Provincetown Center for Coastal Studies in Cape Cod Bay in order to measure the zooplankton populations over a larger spatial area than we could by ourselves. 